\title{
ПОЛИМЕРНЫЕ МАТЕРИАЛЫ
}

УДК 678.743:539.2

DOI:10.35211/1990-5297-2021-10-257-30-33

\section{Н. А. Адаменко, Г. В. Агафонова, Д. А. Ан, А. В. Казуров, В. С. Пироженко ИССЛЕДОВАНИЕ ТЕРМОМЕХАНИЧЕСКИХ СВОЙСТВ СВМПЭ*}

Волгоградский государственный технический университет

e-mail: mvpol@vstu.ru

В работе представлены сравнительные исследования термомеханических свойств сверхвысокомолекулярного полиэтилена (СВМПЭ) и его композита, содержащего 0,5 \% коксографитового порошка (КГП). Установлено, что взрывное прессование давлением 0,25-0,6 ГПа обеспечивает высокую теплостойкость СВМПЭ и исследованного композита $\left(154-156^{\circ} \mathrm{C}\right)$. Теплостойкость композита снижается до $143-145^{\circ} \mathrm{C}$, но $^{\circ}$ она выше, чем у аналогичного материала после статического прессования $\left(128^{\circ} \mathrm{C}\right)$.

Ключевые слова: взрывное прессование, сверхвысокомолекулярный полиэтилен, коксографитовый порошок, композит, термомеханический анализ.

\section{N. A. Adamenko, G. V. Agafonova, D. A. An, A. V. Kazurov, V. S. Pirozhenko STUDY OF THERMOMECHANICAL PROPERTIES OF UHMWPE}

\section{Volgograd State Technical University}

The paper presents comparative studies of the thermomechanical properties of ultra-high molecular weight polyethylene (UHMWPE) and its composite containing $0.5 \%$ coke-graphite powder (CGP). It was found that explosive pressing with a pressure of 0.25-0.6 GPa provides high heat resistance of UHMWPE and the investigated composite $\left(154-156^{\circ} \mathrm{C}\right)$. The heat resistance of the composite decreases to $143-145^{\circ} \mathrm{C}$, but it is higher than that of a similar material after static pressing $\left(128^{\circ} \mathrm{C}\right)$.

Keywords: explosive pressing, ultrahigh molecular weight polyethylene, coke graphite powder, composite, thermomechanical analysis.

\section{Введение}

Серхвысокомолекулярный полиэтилен (СВМПЭ), обладающий уникальным сочетанием эксплуатационных свойств, востребован во многих областях техники и промышленности, которые непрерывно расширяются [1]. Однако сверхвысокая молекулярная масса и низкие значения показателя текучести расплава сдерживают его применение. Улучшить технологичность СВМПЭ удается модификацией его структуры путем высокоэнергетических воздействий на различных стадиях получения и переработки. В последние годы для улучшения технологичности СВМПЭ широко разрабатываются различные методы его модификации: химические [2], механическая активация [3], обработка пучками заряженных частиц [4] и др.
Перспективным способом получения заготовок и изделий из трудноперерабатываемых полимеров, таких как политетрафторэтилен, сверхвысокомолекулярный полиэтилен, полиимиды, фенилоны, полиарилаты, обладающих высокой вязкостью расплава и не переходящих в вязкотекучее состояние при нагреве является взрывное прессование (ВП) [5]. При взрывном прессовании путем выбора определенных технологических параметров обеспечиваются высокие давления (до 10 ГПа), скорости нагружения (до $3000 \mathrm{~m} / \mathrm{c}$ ) и температуры (до $1000{ }^{\circ} \mathrm{C}$ ), что позволяет за счет быстрого протекания различных физико-химических реакций получить структуру и свойства материала, недостижимые другими способами обработки [5-7].

В работе проводили сравнительные исследо-

(C) Адаменко Н. А., Агафонова Г. В., Ан Д. А., Казуров А. В., Пироженко В. С., 2021.

* Работа выполнена при финансовой поддержке гранта РФФИ и Администрации Волгоградской области № 20-0300178. 
вания термомеханических свойств чистого СВМПЭ и наполненного коксографитовым порошком $(0,5 \%)$.

\section{Материалы и методы исследования}

В работе проводили исследования плоских прессовок чистого СВМПЭ и его композита с 0,5 \% КГП после ВП давлением 0,25-0,6 ГПа. Образцы композита для сравнительных исследований были также получены статическим прессованием давлением 0,1 ГПа.

Взрывное прессование проводили по плоской схеме нагружения скользящей ударной волной. Изменение интенсивности взрывного воздействия достигалось применением различных взрывчатых веществ со скоростью детонации от 1680-1960 м/с, что позволило достичь давления ВП 0,25 и 0,6 ГПа, соответственно.

Исследование теплофизических характеристик и деформируемости образцов проводилось термомеханическим испытанием на анализатоpe Netzsch 402 F3 Hyperion по стандартной методике, путем измерения глубины пенетрации индентора (диаметром 1,0 мм) в исследуемый образец с нагрузкой 1 Н в интервале от комнатной температуры до $200{ }^{\circ} \mathrm{C}$. В экспериментах применяли образцы высотой 2 мм, что обеспечивало однородный прогрев в термическом блоке при скорости нагрева 2 град/мин. Термомеханические кривые строились и анализировались с помощью встроенного программного обеспечения Proteus 61.

\section{Результаты исследования}

Термомеханические исследования исходного СВМПЭ (рис. 1, табл. 1) свидетельствуют о незначительных изменениях в термодеформационном поведении полимера при увеличении давления ВП от 0,25 до 0,6 ГПа. Образцы испытывают при нагреве наибольшие деформации 4,3-5,3 \% в интервале температур $145-156{ }^{\circ} \mathrm{C}$, которые обусловлены разрыхлением структуры, свойственные полимеру как после традиционной технологии статического прессования, так и после ВП. В области наибольших деформаций, обусловленных фазовым переходом, на термомеханических кривых (ТМК) выявляется два пика $t_{1}$ и $t_{2}$, что возможно связано с наличием двух кристаллических фаз: орторомбической и моноклинной [8]. Причем температура переходов $t_{1}$ и $t_{2}$ не зависит от величины давления ВП, а меньшие деформации после ВП давлением 0,6 ГПа свидетельствуют об усилении межмолекулярного взаимодействия и интенсификации структурных изменений при более интенсивном ударном воздействии.

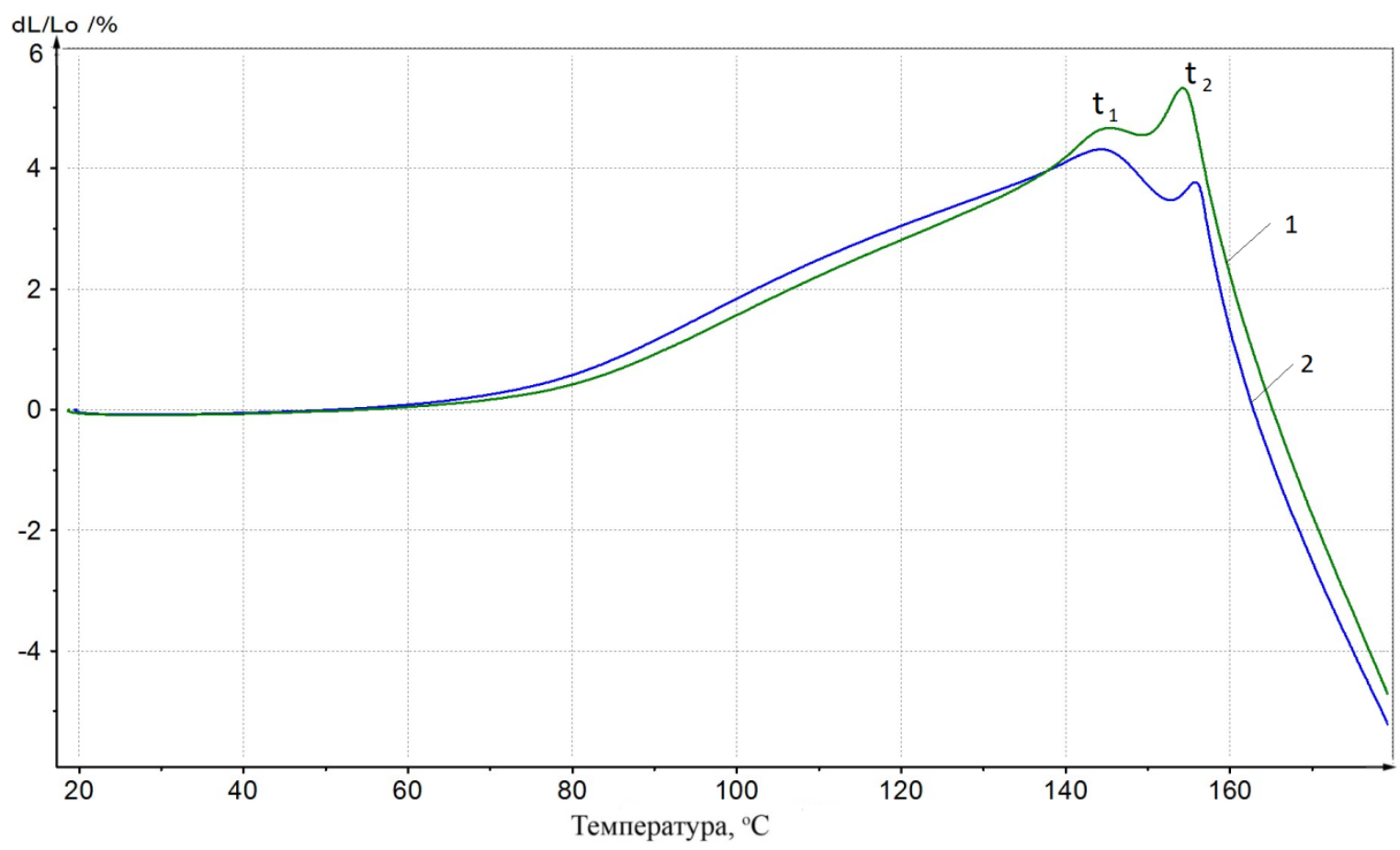

Рис. 1. Термомеханические кривые СВМПЭ после ВП давлением: 
Таблица 1

Термические характеристики СВМПЭ

\begin{tabular}{|c|c|c|c|c|}
\hline $\begin{array}{c}\text { Давление ВП, } \\
\text { ГПа }\end{array}$ & $t_{1},{ }^{\circ} \mathrm{C}$ & $\varepsilon_{1}, \%$ & $t_{2},{ }^{\circ} \mathrm{C}$ & $\varepsilon_{2}, \%$ \\
\hline 0,25 & 145 & 4,7 & 154 & 5,3 \\
\hline 0,6 & 145 & 4,3 & 156 & 3,5 \\
\hline
\end{tabular}

Термомеханические ислледования композита СВМПЭ +0,5 \% КГП свидетельствуют об изменении его термодеформационного поведения как после СП, так и после ВП по сравнению с исходным полимером (рис. 2). При нагреве не зависимо от вида прессования и давления ВП у всех образцов наблюдаются деформации, обусловленные разрыхлением структуры полимера, но максимум значений, соответствующий фазовому переходу полимера, после ВП в 2,2 раза меньше, чем у исходного СВМПЭ. После СП деформации более значительны $(4,8 \%)$ и соответствует чистому СВМПЭ. Таким образом, на- полнитель сдерживает разрыхление структуры полимера, обусловленное малой тепловой подвижностью макромолекул полимера большой молекулярной массы, а возможно и релаксацию предельно сжатых макромолекул. В области плавления полимера отсутствует второй пик, что возможно связано с уменьшением количества моноклинной фазы, содержание которой увеличивается с повышением интенсивности деформаций [8]. Теплостойкость композита после ВП выше, чем после СП на $15-17{ }^{\circ} \mathrm{C}$, что подтверждает более высокое межмолекулярное и адгезионное взаимодействие фаз в исследованном композите после ударной обработки. Однако после ВП плавление композита наблюдается на 11-13 ниже, чем у исходного полимера, что может свидетельствовать о недостаточном межмолекулярном взаимодействии, повысить которое возможно удастся повышением интенсивности обработки.

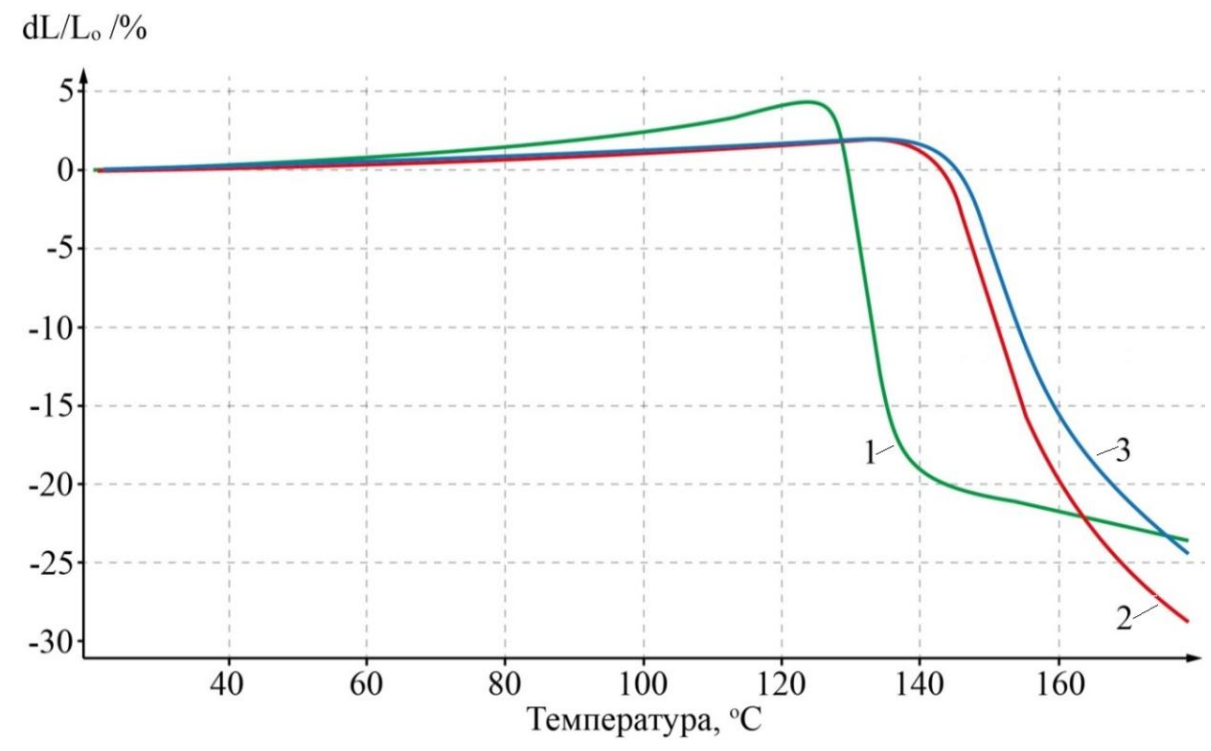

Рис. 2. Термомеханические кривые СВМПЭ + 0,5 \% КГП после СП (1) и ВП давлением: $2-0,25$ ГПа; $3-0,6$ ГПа

Таблица 2

Термические характеристики СВМПЭ + 0,5 \% КГП

\begin{tabular}{|l|c|c|}
\hline \multicolumn{1}{|c|}{ Вид обработки } & $t,{ }^{\circ} \mathrm{C}$ & $\varepsilon, \%$ \\
\hline $\mathrm{C} \Pi, \mathrm{P}=0,1$ ГПа & 128 & 4,8 \\
\hline $\mathrm{BП,} \mathrm{P}=0,25$ ГПа & 143 & 1,9 \\
\hline $\mathrm{BП,} \mathrm{P}=0,6$ ГПа & 145 & 1,8 \\
\hline
\end{tabular}

\section{Выводы}

1. Установлено, что теплостойкость исходного СВМПЭ $\left(154-156{ }^{\circ} \mathrm{C}\right)$ не зависит от давле- ния обработки, а наименьшие тепловые деформации при плавлении полимера (3,5-4,3 \%) наблюдаются после ВП давлением 0,6 ГПа.

2.Выявлено, что после ВП наполнитель сдерживает деформацию СВМПЭ полимера, что подтверждается снижением 2,2 раза термических деформаций, соответствующих фазовому переходу полимера по сравнению с исходным полимером.

3. Установлено повышение теплостойкости композита СВМПЭ + 0,5 \% КГП после ВП на $15-17^{\circ} \mathrm{C}$ по сравнению со статически спрессо- 
ванным, что подтверждает увеличение межмолекулярного и адгезионного взаимодействия фаз после ударной обработки.

\section{БИБЛИОГРАФИЧЕСКИЙ СПИСОК}

1. Михайлин, Ю. А. Сверхвысокомолекулярный полиэтилен / Ю. А. Михайлин // Полим. матер. - 2003. - № 3. C. $18-21$.

2. Zhou, J., \& Yan, F. (2005). Improvement of the tribological behavior of ultra-high-molecular-weight polyethylene by incorporation of poly (phenylp-hydroxyzoate). Journal of Applied Polymer Science, 96(6), 2336-2343. doi:10.1002/app.21534

3. Влияние механической активации, ионной имплантации и типа наполнителей на формирование пленки переноса при трибосопряжении композитов на основе СВМПЭ / С. В. Панин, Л. А. Корниенко, С. Ваннасри, С. Пирияон, Т. Пувадин, Л. Р. Иванова, С. В. Шилько, С. В. Сергеев // Механика композитных материалов. 2011. - T. 47, № 5. - C. 727-738.
4. Modification of ultrahigh-molecular-weight polyethylene by low-temperature plasma (review) / Gilman A.B., Piskarev M.S., Kuznetsov A.A., Ozerin A.N. //High Energy Chemistry. 2017. T. 51. № 2. C. 136-144.

5. Адаменко, Н. Взрывная обработка термостойких полимеров / Н. Адаменко, Г. Агафонова, А. Казуров ; ВолгГТУ. - Волгоград, 2020. - 240 с.

6. Formation of the structure and properties of polyvinylidene fluoride and composites based on it, prepared by explosive pressing / Н.А. Адаменко, Л.Н. Игнатьева, Г.А. Зверев, Г.В. Агафонова, В.А. Мащенко // Journal of Fluorine Chemistry. - 2021. - Vol. 249.

7. Адаменко, H. A. Effect of explosive treatment on the structure and thermomechanical properties of filled polytetrafluoroethylene / Н. А. Адаменко, Г. В. Агафонова // Journal: International Polymer Science and Technology. - 2018. Vol. 45, No. 2. - C. P. 39-42.

8. Влияние ударно-волновой обработки на кристаллическую структуру СВМПЭ / Н. А. Адаменко, Г. В. Агафонова, Д. А. Ан и др. // Известия ВолгГТУ : научный журнал № 9 (219) / ВолгГТУ. - Волгоград, 2018. - (Серия «Проблемы материаловедения, сварки и прочности в машиностроении»). - С. 61-64. 